Kumawula, Vol. 2, No.3, Desember 2019, Hal 211 - 217 DOI:http://10.24198/kumawula.v1i3.24554

ISSN 2620-844X (online)

Tersedia online di http://jurnal.unpad.ac.id/kumawula/index

\title{
PEMANFAATAN LIMBAH PLASTIK UNTUK PEMBUATAN PAVING BLOCK DI DESA CILEUNYI KULON
}

\author{
Dianne Amor Kusuma \\ Departemen Matematika FMIPA Universitas Padjadjaran \\ amor@unpad.ac.id
}

\begin{abstract}
ABSTRAK
Kegiatan KKN tematik Citarum Harum yang berlokasi di Desa Cileunyi Kulon ini secara umum bertujuan untuk menanamkan kepribadian yang kuat pada mahasiswa tentang nasionalisme, jiwa Pancasila, tanggungjawab, kepemimpinan, kewirausahaan, serta meningkatkan empati dan kepedulian mahasiswa secara langsung dengan kehidupan masyarakat. Dalam kegiatan ini yang menjadi fokus perhatian adalah membantu masyarakat mencari solusi dari berbagai permasalahan, salah satunya adalah pengelolaan sampah dan limbah plastik. Berdasarkan hasil survei, wawancara, dan observasi yang dilakukan terhadap masyarakat sekitar Desa Cileunyi Kulon terutama masyarakat sekitar DAS Citarum, bahwa keperdulian masyarakat terhadap pengolahan sampah sangat minim serta banyak terdapat timbunan limbah plastik yang dapat menimbulkan dampak negatif terhadap kesehatan dan mengganggu kelestarian fungsi lingkungan, baik lingkungam pemukiman, hutan, persawahan, dan sungai. Untuk mengurangi volume timbunan limbah plastic yang tidak terkelola dengan baik, maka dilakukan upaya pemanfaatan limbah plastik untuk pembuatan paving block di Desa Cileunyi Kulon. Metode yang dilakukan dalam upaya pemanfaatan limbah plastik ini adalah dengan cara memberikan penyuluhan dan pendampingan pada masyarakat Desa Cileunyi Kulon tentang proses pengumpulan limbah plastik, pengelolaan, serta cara memasarkan hasil pengelolaan limbah plastik secara online. Hasil dari upaya pemanfaatan limbah plastik untuk pembuatan paving block di Desa Cileunyi Kulon ini adalah respon dan antusias masyarakat sangat baik. Agar kegiatan pemanfaatan limbah plastik ini dapat berkelanjutan, maka disarankan untuk memberikan penyuluhan secara rutin pada masyarakat.
\end{abstract}

Kata kunci: Pengelolaan sampah, limbah plastik, paving block, cileunyi kulon.

\section{UTILIZATION OF PLASTIC WASTE TO CREATE PAVING BLOCKS IN CILEUNYI KULON VILLAGE}

\begin{abstract}
The Citarum Harum thematic KKN program, which is located in the village of Cileunyi Kulon, generally aims to instill strong personalities in students about nationalism, the spirit of Pancasila, responsibility, leadership, entrepreneurship, as well as increasing student empathy and concern towards people's lives. In this program the focus of attention is helping the community find solutions to various problems, one of which is the management of waste and plastic waste. Based on the results of surveys, interviews, and observations made on the communities around the village of Cileunyi Kulon, especially communities around the Citarum watersheds, that communities care for waste management is very minimal and there are many piles of plastic waste that can cause negative impacts on health and disturb the preservation of environmental functions, neighborhoods, forests, rice fields, and rivers. To reduce the volume of plastic waste that is not managed properly, an attempt is made to utilize plastic waste for the manufacture of paving blocks in Cileunyi Kulon Village. The method used in the effort to utilize plastic
\end{abstract}


waste is by providing counseling and assistance to the people of Cileunyi Kulon Village about the process of collecting plastic waste, management, and how to market online the results of plastic waste management. The results of efforts to utilize plastic waste for the manufacture of paving blocks in the village of Cileunyi Kulon are very good response and enthusiasm of the community. So that the utilization of plastic waste can be sustainable, it is advisable to provide regular counseling to the community of Cileunyi Kulon village.

Keywords: Waste management, plastic waste, paving blocks, cileunyi kulon.

\section{Pendahuluan}

Pendidikan lingkungan hidup (environmental education) adalah suatu proses untuk membangun seluruh umat manusia di dunia yang sadar dan peduli terhadap lingkungan dan segala masalah yang berkaitan dengannya. Permasalahan tersebut tidak terlepas dari masyarakat yang memiliki pengetahuan, ketrampilan, sikap dan tingkah laku, motivasi serta komitmen untuk bekerja sama untuk dapat memecahkan berbagai masalah lingkungan saat ini dan mencegah timbulnya masalah baru. Pendidikan lingkungan hidup juga memasukkan aspek afektif yaitu tingkah laku, nilai dan komitmen yang diperlukan untuk membangun masyarakat yang berkelanjutan.

Sesuai dengan ketentuan yang ditetapkan pada Pasal 5 UU Pengelolaan Lingkungan Hidup No. 23 Tahun 1997, bahwa masyarakat berhak atas Lingkungan hidup yang baik dan sehat. Untuk mendapatkan hak tersebut, pada pasal 6 dinyatakan bahwa masyarakat dan pengusaha berkewajiban untuk berpartisipasi dalam memelihara kelestarian fungsi lingkungan, mencegah dan menanggulangi pencemaran dan kerusakan lingkungan. Terkait dengan ketentuan tersebut, dalam UU No. 18 Tahun 2008 secara eksplisit juga dinyatakan, bahwa setiap orang mempunyai hak dan kewajiban dalam pengelolaan sampah. Dalam hal pengelolaan sampah pasal 12 dinyatakan, setiap orang wajib mengurangi dan menangani sampah dengan cara berwawasan lingkungan.

Pengelolaan sampah bertujuan untuk meningkatkan kesehatan masyarakat dan kualitas lingkungan serta menjadikan sampah sebagai sumberdaya. Dari sudut pandang kesehatan lingkungan, pengelolaan sampah dipandang baik jika sampah tersebut tidak menjadi media berkembang biaknya bibit penyakit serta sampah tersebut tidak menjadi medium perantara menyebarluasnya suatu penyakit. Syarat lainnya yang harus dipenuhi, yakni tidak mencemari udara, air dan tanah, tidak menimbulkan bau (tidak mengganggu nilai estetis), tidak menimbulkan kebakaran dan yang lainnya (Kusminah, 2018). Pengelolaan sampah di Desa 
Cileunyi Kulon pun memiliki faktor-faktor pendorong dan penghambat dalam upaya peningkatan partisipasi masyarakat dalam pengelolaan sampah.

Masyarakat harus berpartisipasi dalam proses pengambilan keputusan, pengelolaan dan pengawasan di bidang pengelolaan sampah. Tata cara partisipasi masyarakat dalam pengelolaan sampah dapat dilakukan dengan memperhatikan karakteristik dan tatanan sosial budaya daerah masing-masing. Berdasarkan ketentuan tersebut, tentu menjadi kewajiban dan hak setiap orang baik secara individu maupun secara kolektif, demikian pula kelompok masyarakat pengusaha dan komponen masyarakat lain dan khususnya di Desa Cileunyi Kulon untuk berpartisipasi dalam pemanfaatan dan pengelolaan sampah dalam upaya untuk menciptakan lingkungan yang baik, bersih, dan sehat.

Pengolahan sampah membutuhkan lahan sebagai tempat pembuangan akhir (TPA). Sampah sebagai barang yang masih bisa dimanfaatkan tidak seharusnya diperlakukan sebagai barang yang menjijikkan, melainkan harus dapat dimanfaatkan sebagai bahan mentah atau bahan yang berguna lainnya. Seharusnya pengolahan sampah harus dilakukan dengan efisien dan efektif, yaitu sebisa mungkin dekat dengan sumbernya, seperti di lingkungan RT/RW, sekolah, dan rumah tangga sehingga jumlah sampah dapat dikurangi.

Desa Cileunyi Kulon merupakan salah satu desa yang berada di wilayah Kabupaten Bandung Kecamatan Cileunyi yang merupakan pemekaran dari Desa Cileunyi Wetan, yang dirintis pada tahun 1978. Luas wilayah desa Cileunyi Kulon 489,17 hektar terbagi dalam wilayah administratif 8 Dusun, 26 wilayah Rukun Warga (RW) dan 116 wilayah Rukun Tetangga (RT). Jumlah penduduk desa Cileunyi Kulon pada akhir Desember 2018 berjumlah 22.002 jiwa. Mayoritas penduduk bekerja sebagai petani, buruh, pegawai swasta, pengrajin, pedagang, montir dan lain-lain. Pelaksanaan kegiatan KKN dilakukan dengan melakukan berbagai upaya mulai dari sosialisasi pengelolaan sampah pada para perangkat desa dan masyarakat guna memanfaatkan limbah plastik di lingkungan sekitar pemukiman masyarakat.

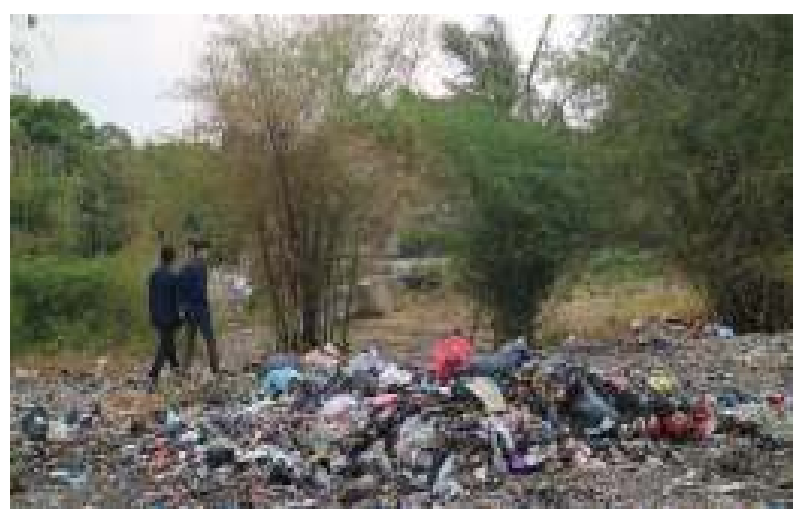

Gambar 1. Kondisi Sampah di Desa Cileunyi Kulon 
Masyarakat di Desa Cileunyi Kulon membutuhkan tempat pembuangan sampah di tempat-tempat strategis serta TPS maupun TPA. Hal ini terlihat dari banyaknya sampah yang berserakan, terutama limbah plastik, di lingkungan sekitar karena kurangnya fasilitas pembuangan sampah. Permasalahan yang dihadapi desa Cileunyi Kulon saat ini yakni tidak adanya pengolahan limbah plastik yang dihasilkan masyarakat serta kurangnya minat masyarakat dalam mengolah limbah plastik yang ada untuk pembuatan paving block. Dipilih paving block karena berdasarkan pengamatan, PET (polyethylene therepthalate) dapat digunakan dengan 50\% debu tambang dan 25\% fly ash untuk campuran paving block berbahan dasar plastik (Nivetha, et. al., 2016). Berdasarkan latar belakang masalah tersebut, maka penulis tertarik untuk mengolah limbah plastik yang ada di Desa Cileunyi Kulon.

\section{METODE}

Metode yang dilakukan pada kegiatan KKN tematik Citarum Harum di Desa Cileunyi Kulon dalam upaya pemanfaatan limbah plastik adalah dengan cara melakukan wawancara dan survei pada masyarakat, melakukan observasi, serta memberikan penyuluhan dan pendampingan pada masyarakat. Materi penyuluhan yang diberikan adalah mengenai proses pengumpulan limbah plastik, pengelolaan, serta cara memasarkan hasil pengelolaan limbah plastik secara online. Sasaran kegiatan ini adalah seluruh masyarakat Desa Cileunyi Kulon, karena mereka adalah penyumbang limbah plastik terbesar di Desa Cileunyi Kulon. Instrumen yang digunakan dalam kegiatan ini meliputi: angket yang disebarkan pada masyarakat dan materi penyuluhan.

Adapun pelaksanaan kegiatan ini terdiri atas empat tahap, yakni tahap perencanaan, tahap persiapan, tahap pelaksanaan, dan tahap evaluasi. Tahap perencanaan kegiatan terdiri atas: 1) melakukan wawancara dan survei; 2) melakukan observasi; dan 3) melakukan kesepakatan kerjasama dengan pengepul sampah plastik. Tahap persiapan meliputi penyusunan jadwal kegiatan, serta pembelian peralatan dan bahan untuk pelaksanaan program. Tahap pelaksanaan meliputi pelaksanaan pelatihan yang berkenaan dengan pengelolaan sampah dan cara memasarkan hasil pengelolaan limbah plastik (dalam hal ini, paving block) secara online. Selanjutnya adalah tahap evaluasi yang dilakukan untuk mengetahui pencapaian masyarakat Desa Cileunyi Kulon berkenaan dengan pengelolaan limbah plastik pada pembuatan paving block. Tahap ini diukur berdasarkan proses usaha yang berkelanjutan, serta peningkatan kreativitas masyarakat dalam mengolah limbah plastik menjadi paving block. Indikator keberhasilan pada tahap evaluasi ini dilihat berdasarkan berkurangnya limbah plastik serta 
peningkatan pendapatan masyarakat atas adanya pengolahan limbah plastik serta terbukanya lapangan pekerjaan.

\section{HASIL DAN PEMBAHASAN}

Paving block adalah material yang serba guna, menarik secara estetika, fungsional, efektif, dan tidak memerlukan atau sedikit pemeliharaan jika diproduksi dan dipasang dengan benar. Kebanyakan paving block beton juga sudah mampu berperan dengan baik dalam pembangunan, namun ada dua perhatian utama dalam penggunaannya yaitu kegagalan di permukaan karena pemakaian berlebih dan juga variasi dari kekuatan paving block beton. Sumber daya alam secara global sedang mengalami penurunan dan di saat yang sama limbah dan sampah yang dihasilkan oleh industri dan rumah tangga semakin meningkat. Pengembangan berkelanjutan di bidang konstruksi salah satunya adalah dengan menggunakan bahan yang non-konvensional dan inovatif, dan juga daur ulang dari bahan limbah serta sampah untuk mengurangi penggunaan sumber daya alam dan menemukan alternatif dalam melestarikan alam.

Nivetha, et. al., (2016) membuat sebuah percobaan untuk menggunakan ulang debu tambang dan PET (polyethylene therepthalate) dengan tujuan untuk membuat paving block yang memiliki kekuatan mirip dengan paving block semen. Dari hasil pengamatan, PET dapat digunakan dengan 50\% debu tambang, dan 25\% fly ash dalam campuran paving block plastik. Properti fisikawi dan mekanis dari bahan yang digunakan kemudian diinvestigasi. Untuk percobaan, 6 paving block dibuat dan kemudian diuji kekuatannya dengan uji kompresi. Tapkire, et. al. (2016) menggunakan agregat dari berbagai campuran plastik dan pasir untuk melihat kestabilannya. Jumlah plastik yang dihasilkan di abad 21 telah menciptakan tantangan besar perihal pembuangannya, maka dari itu usaha dari berbagai pihak untuk menciptakan penggunaan dari sampah plastik ini sangatlah penting, terutama di industri konstruksi yang semakin berkembang. Sharma dan Batra (2016) pun dalam penelitiannya telah membahas penggunaan paving block semen untuk jalan umum. Shantosh dan Talluri (2015) mengindikasikan bahwa campuran fly ash dan limbah serbuk kaca dapat digunakan secara efektif untuk pengganti semen tanpa perubahan kekuatan.

Langkah pertama pembuatan paving block ini ialah mencacah sampah plastik. Satu buah paving block membutuhkan lima sampai tujuh kilogram sampah plastik. Setelah alat pelebur dipanaskan, kemudian sampah plastik dan limbah pertanian (sekam padi dan serbuk kayu) dimasukan kedalam alat pelebur untuk dilelehkan lalu dicampur dengan pasir dengan komposisi 30:20:60 lalu diaduk pada suhu 300 hingga 400 derajat celsius, selama 30-45 menit. Pasir 
berfungsi sebagai pemberat, agar saat terendam air tidak mengambang. Setelah semua bahan melebur kemudian dimasukan ke dalam cetakan dan di-press agar mengikuti bentuk cetakan. Selanjutnya, paving block yang telah terbentuk didiamkan beberapa saat lalu dimasukkan ke dalam air untuk didinginkan. Hasil paving block dapat diwarnai menggunakan cat karena paving block yang dihasilkan berwarna hitam. Setelah itu, paving block siap untuk dipasarkan.

Dengan diproduksinya paving block yang berasal dari olahan limbah plastik, diharapkan banyak manfaat yang diperoleh msayarakat di Desa Cileunyi Kulon, antara lain: a) jumlah limbah plastik dapat dikurangi; b) kebersihan lingkungan dan keberlanjutan alam dapat lebih terjaga; dan c) dapat menciptakan lapangan kerja bagi masyarakat Desa Cileunyi Kulon. Kegiatan yang dilakukan di Desa Cileunyi Kulon dalam upaya pengelolaan limbah plastik untuk pembuatan paving block yakni melaksanakan penyuluhan pada masyarakat Desa Cileunyi Kulon serta memberikan pendampingan pada masyarakat Desa Cileunyi Kulon. Hasil dari kegiatan ini adalah respon serta antusias masyarakat yang sangat baik, yang diperlihatkan dengan perubahan perilaku mereka terhadap limbah plastik, sebagai contoh: mereka mulai memilah dan mengelompokkan sampah yang ada di tempat tinggal mereka, serta mengumpulkan limbah plastik dan tidak membuangnya sembarangan.

\section{SIMPULAN}

Masalah utama di Desa Cileunyi Kulon adalah kurang pedulinya masyarakat terhadap sampah, terutama limbah plastik, yang mana hingga saat ini masyarakat masih memiliki kebiasaan membuang sampah sembarangan, membakar sampah, serta masih kurangnya pengetahuan masyarakat mengenai pengelolaan sampah yang tepat, sehingga menyebabkan polusi udara dan berdampak buruk pada kesehatan. Oleh karena itu, sasaran program dari kegiatan KKN tematik Citarum Harum 2019 di Desa Cileunyi Kulon ini adalah melakukan pemanfaatan limbah plastik yang dapat diolah menjadi produk yang bernilai, salah satunya adalah paving block. Dengan adanya kegiatan ini maka masyarakat Desa Cileunyi Kulon menjadi lebih peduli lingkungan dengan cara tidak membuang sampah sembarangan dan memilah serta mengumpulkan limbah plastik untuk diolah menjadi paving block. Agar keberlanjutan dari kegiatan ini tetap terjaga, maka perlu secara rutin diberikan penyuluhan pada masyarakat Desa Cileunyi Kulon berkenaan dengan informasi-informasi terbaru tentang proses pemanfaatan limbah plastik untuk pembuatan paving block, serta cara memasarkan paving block tersebut tidak hanya di wilayah Desa Cileunyi Kulon, bahkan dapat merambah ke seluruh wilayah Indonesia. 


\section{UCAPAN TERIMA KASIH}

Paper ini merupakan hasil Pengabdian Kepada Masyarakat pada kegiatan KKN Tematik Citarum Harum tahun 2019, yang terselenggara berkat kerjasama Universitas Padjadjaran dan Direktorat Jendral Pembelajaran dan Kemahasiswaan Kemenristekdikti tahun 2019. Ucapan terima kasih disampaikan kepada Rektor Universitas Padjadjaran, Dirjen Belmawa Kemenristekdikti, Satgas Citarum Harum, serta tim mahasiswa KKN Citarum Harum Desa Cileunyi Kulon, yakni Adam Kevin Jonathan, Yusi Utami Indriyati, Hasan Prasetyo Hutomo, Fitri Fitriani, Hafizh Naufal Suryandani, Belva Ilaika Rahmadini, Asma Hasanah, Navila Ulfa Aisya, Rana Pauliyanti Putri, Rizki Afilla Darmawan, Gabriela Tamara, Sonia Putri, Sarah Khairunnisa Anwar, Amarif Abimanyu, Primus Metafaty Daeli, Zaidhiya Rizqi Raihani, M. Izzi Kusfawzan, Monica Lintang, Fajar Abdullah, dan Ario Jamesbond, juga Camat Cileunyi, Kepala Desa dan Sekretaris Desa Cileunyi Kulon, serta seluruh masyarakat Desa Cileunyi Kulon.

\section{DAFTAR PUSTAKA}

Kusminah, I. L. 2018. Penyuluhan 4R (Reduce, Reuse, Recycle, Replace) dan Kegunaan Bank Sampah sebagai Langkah Menciptakan Lingkungan yang Bersih dan Ekonomis di Desa Mojowuku Kabupaten Gresik. Jurnal Pengabdian Masyarakat LPPM Untag Surabaya, 3(1): $22-28$.

Nivetha, C., Rubiya, M., Shobana, S., \& Vaijayanathi, G. (2016). Production of Plastic Paver Block from the Solid Waste. ARPN Journal of Engineering and Applied Science. 11(2): 56-67.

Santhosh, J., \& Talluri, R. (2015). Manufacture of Interlocking Concrete Paving Blocks with Fly

Ash and Glass Powder. International Journal of Civil Engineering and Technology, 6(4): 5564.

Sharma, P., \& Batra, R. K. (2016). Cement Concrete Paver Blocks for Rural Roads. International Journal of Current Engineering and Scientific Research, 3(1): 114-121.

Tapkire, G., Parihar, S., Patil, P., Hemra, \& Kumavat, R. (2014). Recycled Plastic used in Concrete

Paver Block. International Journal of Research in Engineering and Technology, 3(09): 103112. 